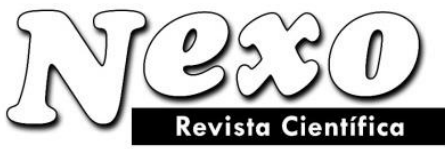

ISSN-E 1995-9516

Universidad Nacional de Ingeniería COPYRIGHT @ (UNI). TODOS LOS DERECHOS RESERVADOS http://revistas.uni.edu.ni/index.php/Nexo https://doi.org/10.5377/nexo.v34i06.13139

\title{
On the relationship between fundamental science and contemporary applied research in the field of high-rate laser Nanowhiskerography
}

\section{Sobre la relación entre la ciencia fundamental y la investigación aplicada contemporánea en el campo de la Nanowhiskerografía láser de alta velocidad}

\author{
Sergey Nikoloaevich Maksimovsky ${ }^{1,2 *}$, Alexandr Nikolaevich Bobkov ${ }^{3}$, Aleksey Urievich \\ Stavtsev $^{1}$ \\ ${ }^{1}$ K.G. Razumovsky Moscow State University of technologies and management (the First Cossack \\ University). Moscow. Russia. \\ ${ }^{2}$ Universal Laser Systems, Inc., USA \\ ${ }^{3}$ Russian State Geological Prospecting University named after Sergo Ordzhonikidze, Russia \\ *email: s.n.maksimovsky@mail.ru
}

(recibido/received: 22-septiembre-2021; aceptado/accepted: 02-diciembre-2021)

\begin{abstract}
In practice, in various areas of life, there is often a need to use materials that have mutually exclusive requirements. Therefore, the study of the issues related to manufacturing materials in certain states for certain technical applications, and methods of controlling structurally sensitive properties to obtain specified effects, is quite relevant today. A new effect was discovered, namely, the rapid growth of amorphous and composite materials in the form of "coherent" nanowhiskers using laser-induced plasma at temperatures exceeding $4,000^{\circ} \mathrm{C}$ and high pressures up to 100 thousand atmospheres at a rate reaching 80$100 \mathrm{~m} / \mathrm{s}$. This method of growing whiskers is based on fundamental studies of pulsed laser radiation and predictions of Nobel Prize laureates - Ch.H. Townes, A.M. Prokhorov (splitting of a laser beam of abovethreshold power) and G.A. Askaryan (effects of self-focusing of light in the condensed state of matter, and sublimation evaporation). The authors show possible practical applications of this method, such as protection of securities, banknotes, and plastic cards, as well as production of a new type of silicon batteries, automotive catalysts, and solar silicon batteries.
\end{abstract}

Keywords: nanoscale crystallization; self-focusing; above-threshold power; multilayer film structures.

\section{RESUMEN}

En la práctica, en diversas áreas de la vida, a menudo existe la necesidad de utilizar materiales que tengan requisitos mutuamente excluyentes. Por tanto, el estudio de las cuestiones relacionadas con la fabricación de materiales en determinados estados para determinadas aplicaciones técnicas, y los métodos de control de propiedades estructuralmente sensibles para obtener efectos especificados, es bastante relevante en la actualidad. Se descubrió un nuevo efecto, a saber, el rápido crecimiento de materiales amorfos y compuestos en forma de nanowhiskers "coherentes" utilizando plasma inducido por láser a temperaturas superiores a $4.000 \mathrm{oC}$ y altas presiones de hasta 100 mil atmósferas a una velocidad que alcanza los 80-100 $\mathrm{m} / \mathrm{s}$. Este método de crecimiento de bigotes se basa en estudios fundamentales de la radiación láser pulsada y en las predicciones de los premios Nobel, Ch.H. Townes, A.M. Prokhorov (división de un rayo 
láser de potencia por encima del umbral) y G.A. Askaryan (efectos del autoenfoque de la luz en el estado condensado de la materia y la evaporación por sublimación). Los autores muestran posibles aplicaciones prácticas de este método, como la protección de valores, billetes y tarjetas plásticas, así como la producción de un nuevo tipo de baterías de silicio, catalizadores automotrices y baterías solares de silicio.

Palabras claves: cristalización a nanoescala; autoenfoque; potencia por encima del umbral; estructuras de película multicapa.

\section{INTRODUCCIÓN}

"Philosophy gives instructions how research should be conducted" - this ancient Greek judgment of Aristotle is absolute truth. The content of the philosophical truth is that research should be aimed at changing human practice. There is no doubt that science is not just a growing array of empirical information about the world and a sequence of changing theories. Science is also an evolution of our conceptual approaches to the use of scientific research. This is a continuous search for the best conceptual structure in the science-practice-human paradigm. And the modification of the conceptual structure should be manifested within the framework of modern scientific research.

It is quite obvious that one of the reasons for the relative infecundity of theoretical physics over the past few decades may be precisely the fact that today many physicists adhere to the "wrong" philosophy of science. Popper and Kuhn, so popular among theoretical physicists, absolutized important aspects of how "good science" works, but, taken uncritically, their ideas ultimately mislead researchers. Kuhn's emphasis (Kumn, 1962) on the paradigm gap and incommensurability has misled many theoretical and experimental physicists, devaluing huge aggregate aspects of scientific knowledge. Popper's emphasis on falsifiability (Popper, 1959), initially assumed as a criterion for the demarcation of science was categorically misinterpreted as an evaluation criterion. Their combination led to a catastrophic methodological confusion: the idea arose that past knowledge does not matter when searching for new theories, that all unproven ideas are equally interesting and all immeasurable effects are equally likely, and that the job of a theorist is to pull arbitrary probabilities out of nowhere and develop them, since everything that has not yet been falsified may be correct.

This work is aimed at changing human practice to reach a socially positive effect since it contains a deep socio-transformative potential and expands the human possibilities in contemporary technological practice. We hope that our research will receive a proper assessment among specialists and will be widely used, first of all, in contemporary energy-saving technologies, which will undoubtedly lead to a new quality of using natural resources and human worldview standpoints.

To develop the advanced technologies, and discoveries that would change the overall situation in the world, it is necessary to rest on great scientists, their theoretical schools that will lead to revolutionary discoveries in science and technology. This explains the growing role in the creation of breakthrough technologies in various technical fields, including electronics, semiconductor technology, and the printing industry. Field-effect transistors, light-emitting diodes, ultrafast integrating circuits (IC) with a resolution of 20-60 nm, and single-chip optoelectronic components are based on nanowhiskers. Present-day technological achievements are based on the works performed by Ch. Libor (Harvard University, USA), L. Samuelson (Lund University, Sweden), and E.I. Givargizov (Shubnikov Institute of Crystallography, Russia) devoted to the vapor-liquid-crystal mechanism (Givargizov y Chernov, 1973).

However, in this case, the growth rate of nanowhiskers is low, equal to 5 microns/hour, while the process requires special equipment, which excludes the possibility of growing in the open air. 
With the invention of lasers, a new area in the physics of the interaction of radiation with matter, as well as technologies of laser processing of materials has emerged (Koshelev, et al. 2016; Kudryashov y Lyon y Allen, 2006). The development of this field continues at present with regard to growing structures by modifying the surface under the impact of laser radiation (Honma, 2010; Zohuri, 2021; Qibiao, et al. 2019).

New technology for the outdoor growth of nanowhiskers using high-power pulsed laser radiation (average power of $40 \mathrm{~W}$, pulse repetition rate of $3-30 \mathrm{kHz}$, pulse duration from $10 \mathrm{~ns}$ to one ms, temperature $<4,000^{\circ} \mathrm{C}$, and crystallization growth rate of $80-100 \mathrm{~m} / \mathrm{s}$ ) was developed at the Moscow State University of Technology and Management named after K. G. Razumovsky and the Lebedev Physical Institute.

The developed technology is based on fundamental studies of Nobel Prize laureates - Ch.H. Townes (USA), A.M. Prokhorov (USSR), and G.A. Askaryan. Calculations and direct measurements of the pulsed laser radiation power have shown that super-threshold irradiation was used in the conducted experiments.

According to Askaryan, "Above-threshold power is the power at which nonlinear reflection and diffraction divergence are commensurable, and can compensate for each other" (Askaryan, 1974). In his work, Townes has shown that at above-threshold powers, a laser beam can be split into numerous constituent beams with the same threshold power (Chiao y Garmire y Townes, 1964). According to Askaryan, self-focusing occurs not only in liquids but also in plastics, since the corresponding parameters are quite similar. Electrons are strongly ejected from the beam, which leads to a spatial charge and the departure of ions from the beam. At the same time, the atoms are pushed out of the beam (Bogonosov $y$ Maksimovsky, 2011). The effect of sublimation evaporation, discovered by Askaryan and Morozov, shows that the recoil pressure during the evaporation of the material under the impact of laser radiation pulses is thousands and tens of thousands of times higher than the light pressure (Askaryan y Moroz, 1962).

The developed technology ensures the growth of metal nanowhiskers based on pure metals and their alloys (Maksimovsky y Radutsky, 2014a), metal oxides and metalloids, as well as semi-precious stones that cannot crystallize under normal terrestrial conditions (Maximovskii et al. 2016). Using this technology, unique images were obtained on protected securities, passports, and other securities with strong protective properties (Maksimovsky y Radutsky, 2004).

The purpose of the work is to study the growing processes of ordered structures on the surface of amorphous materials (plastic, glass) in the form of whiskers.

\section{METHODS}

Before proceeding to the technology description, it was necessary to make sure that the idea of Townes and Prokhorov about splitting an above-threshold laser beam into threshold laser beams was correct. To do this, the following experiments were carried out. A thin aluminum foil was glued to the plastic surface, and several irradiations were carried out with a fiber-optic laser with an average power of $26 \mathrm{~W}$. The process of splitting a laser beam with a power above the threshold into several beams of limited power that penetrate the lower plastic layer is shown in the photo (Figure 1) taken using an atomic force microscope idea of Towns).

The substrates were irradiated with focused pulsed radiation of an Nd:YAG- laser at a wavelength of 1.064 microns.

The obtained samples were examined using optical microscopy and Certus Light V laser-scanning probe microscope (atomic force microscope), manufactured by Nano ScanTech. 


\section{RESULTS}

In the optical microscopic observations, the points of laser shots were doubled (Figure 2). According to the image, these spots have the form of ordered reproducible formations in the irradiation zone, which have the form of double channels with a size of $0.2-0.3 \mathrm{~mm}$ each. It is important that the channels have the same shape, and the interface zones between them are the same size. The surfaces of the irradiated samples and the structure of the channels were studied more thoroughly by atomic force microscopy. The relief of the channel bottom at the laser shot spots and the distance between the points were studied. The results are shown in Figure 3. For the first time, the doubling of ordered structures was observed in (Askaryan, 1974). It can be seen from the data of atomic force microscopy (Figure 3) that the boundary zone "a" between the crystals represents a specific array of "particles" of peaks with a height of 0.5-1 microns with nanoscale peaks. The largest formations have a size of 5 microns.

During the crystallization of shattuckite, observed self-focusing of the laser beam, and the generation of moving foci initiate the beginning of crystallization, followed by the growth of equally oriented crystals (Bogonosov y Stavtsev y Maksimovsky, 2018).

The corresponding optical images are shown in Figure 5.

It is quite possible that this "palisade" characterizes the crystal structure of the glass surface that remains under the impact of a laser pulse. Interestingly, not only the size and shape of the channels from laser pulses are symmetrical about to the boundary zone of the "palisade", but also the array of peaks is not located randomly, and is characterized by a noticeable symmetry about the boundary "palisade", forming a mirror image.

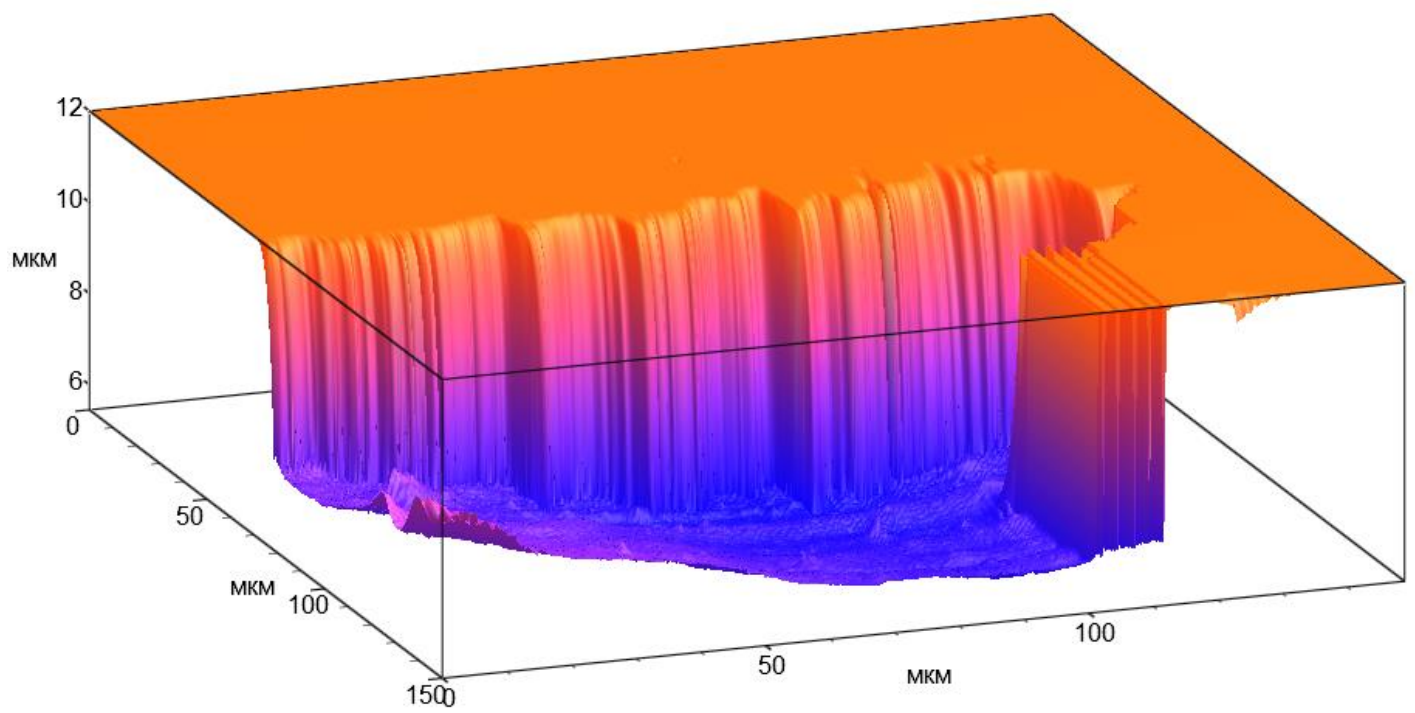

Figure 1. Splitting of the laser beam of above-threshold power (Towns' idea) 


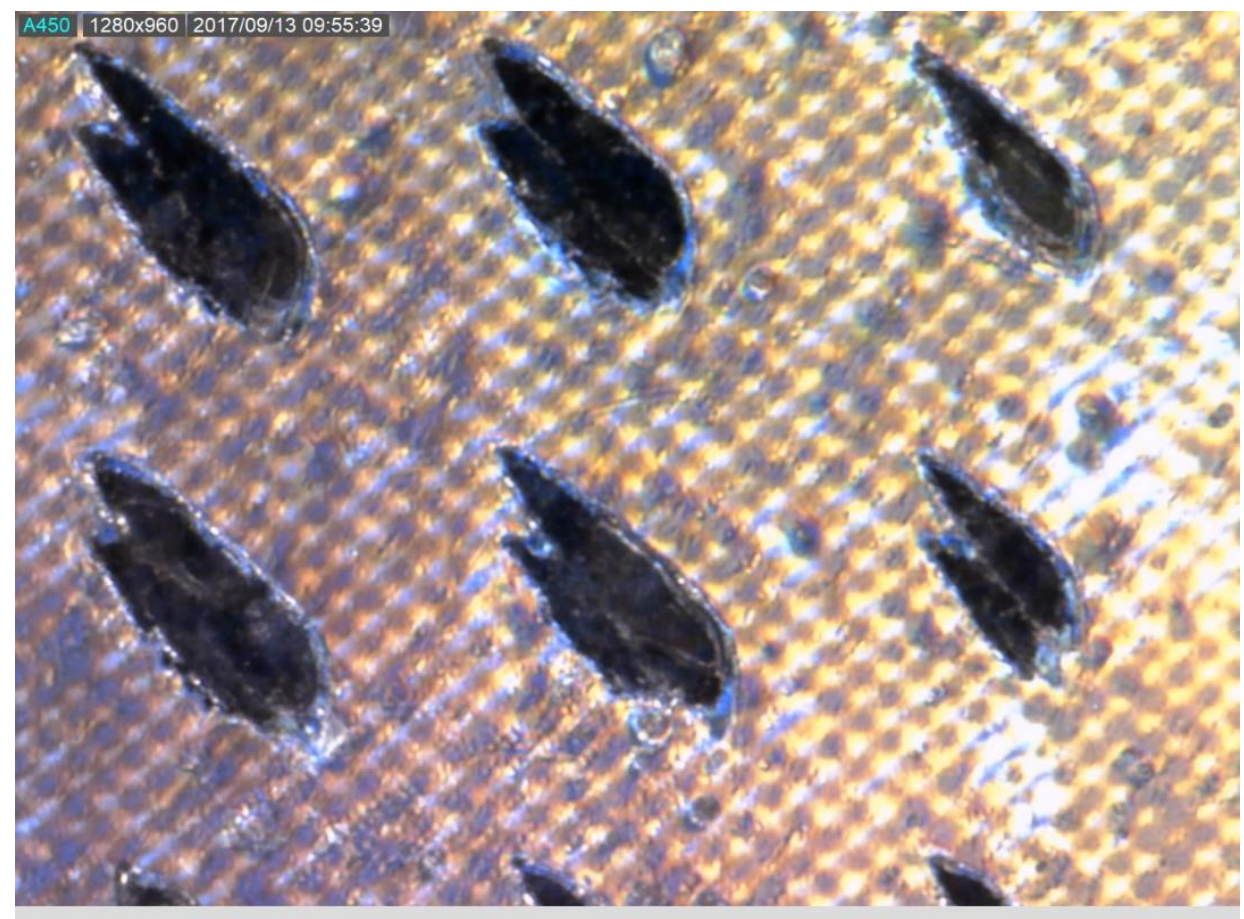

Figure 2. The surface area after laser radiation (optical microscope, magnification $\times 500$ )

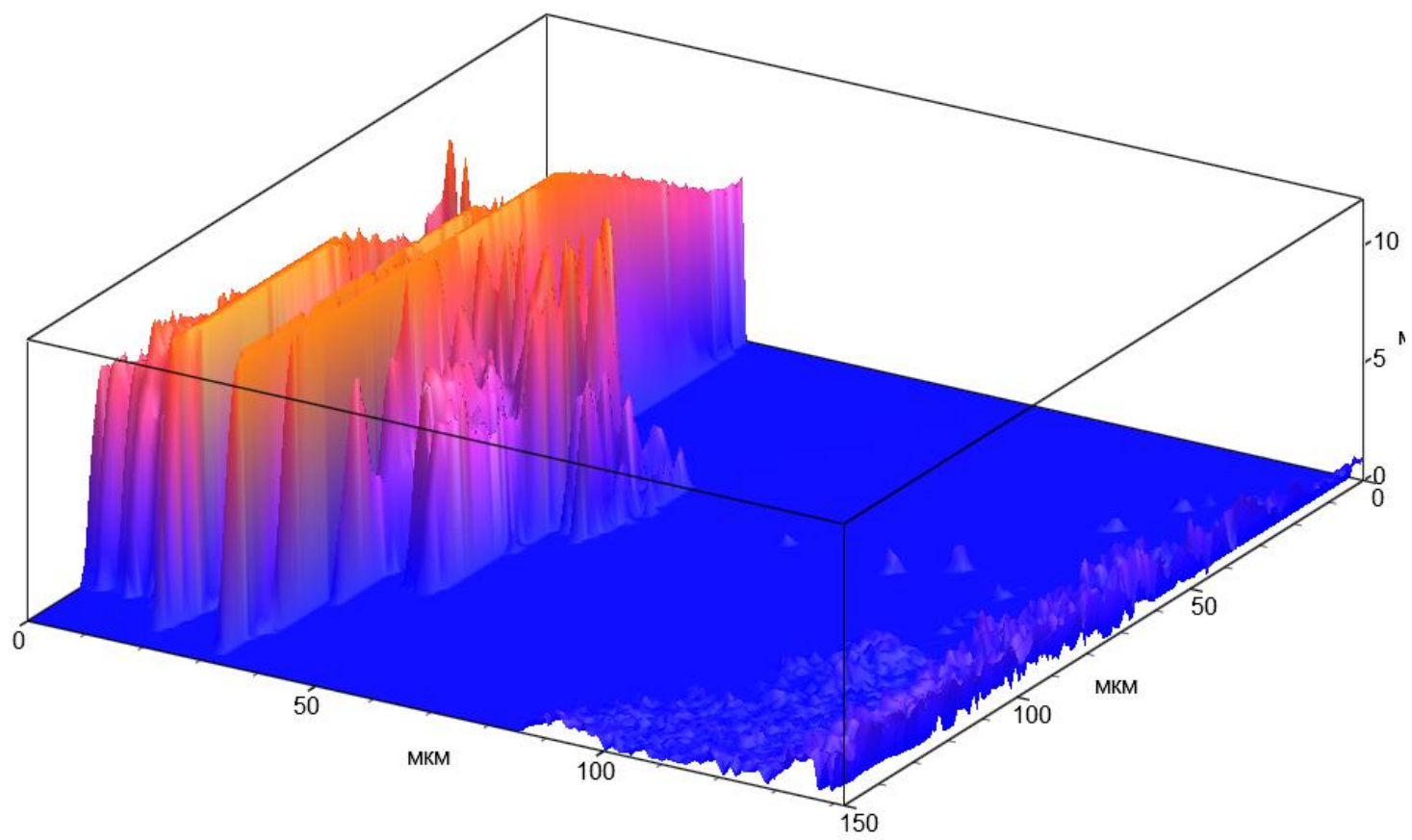

Figure 3. "Palisades" in the boundary zone, and symmetrical zone on the carbon surface with a silicone coating (atomic force microscope)

\section{DISCUISSION}

The conducted experiments led us to the conclusion that two phenomena are observed under the impact of laser radiation on a specially prepared substrate: rapid crystallization of the material (copper shattuckite), 
on the one hand, and the formation of nanowhiskers on the other hand. Estimates show that the laser pulse power was above-threshold, while direct measurements and calculations show that crystallization occurred within the temperature range $<4,000^{\circ} \mathrm{C}$ at a pulse pressure of $<10^{5} \mathrm{~atm}$. We assume that the observed phenomena are related to the fundamental research of Towns, Prokhorov, and Askaryan. However, more accurate calculations will confirm these assumptions.

According to Askaryan, self-focusing occurs not only in liquids but also in plastics, since water and plastics have almost similar refractive indices (in this case, electrons are strongly ejected from the beam, which leads to a spatial charge and the departure of ions from the beam).

At the same time, the atoms are pushed out of the beam (Askaryan, 1974). A similar effect is observed when phase-shifted coherent beams are exposed to irradiation of composite materials. The conducted studies show that two nanowhisker ridges appear under the impact of two beams; in the central zones of the beams, there are only isolated nanowhiskers that are symmetrical about the ridge. Under the impact of counter-propagating laser beams, the concentration of nanowhiskers increases tenfold.
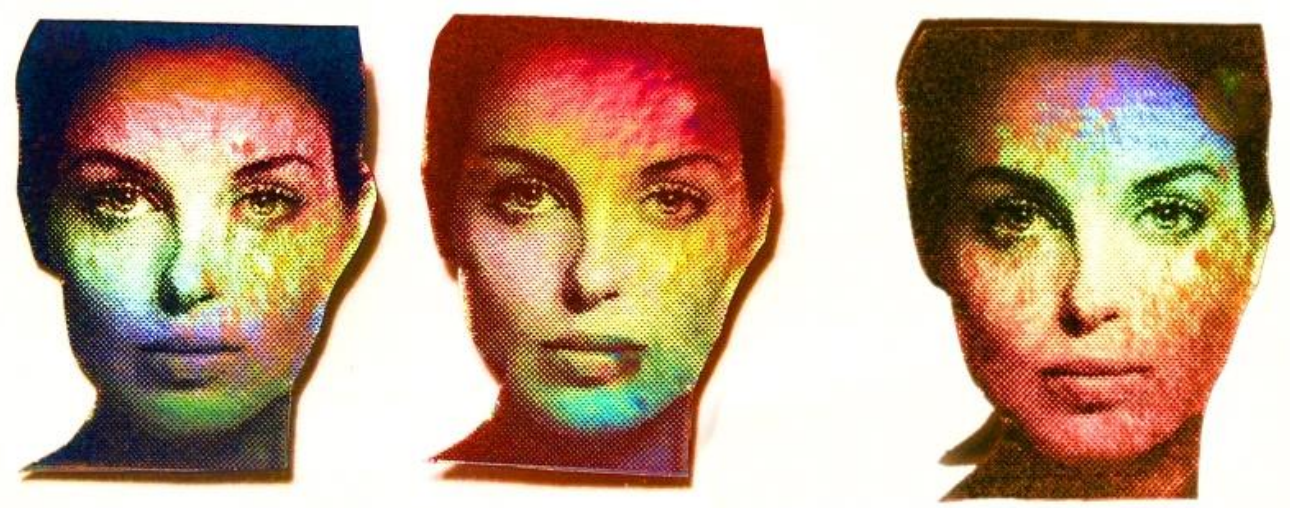

a)

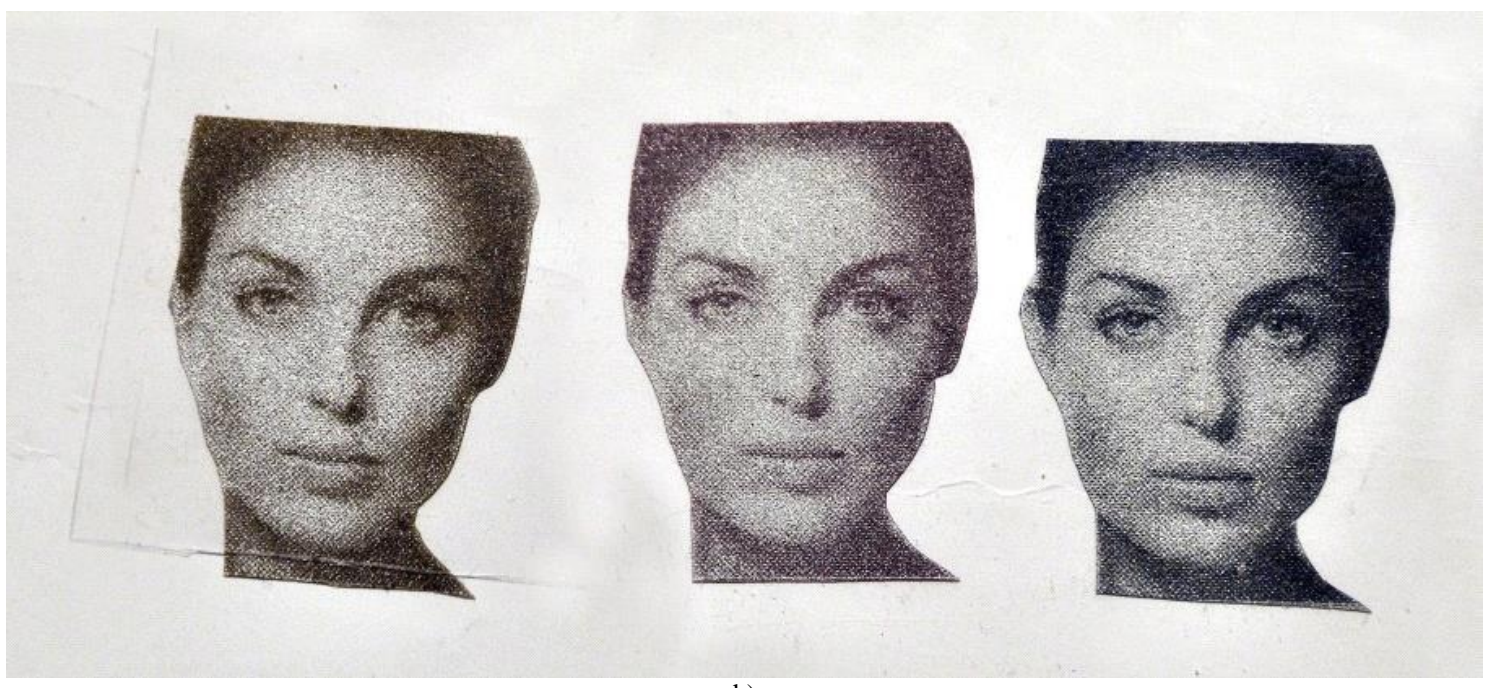

b) 

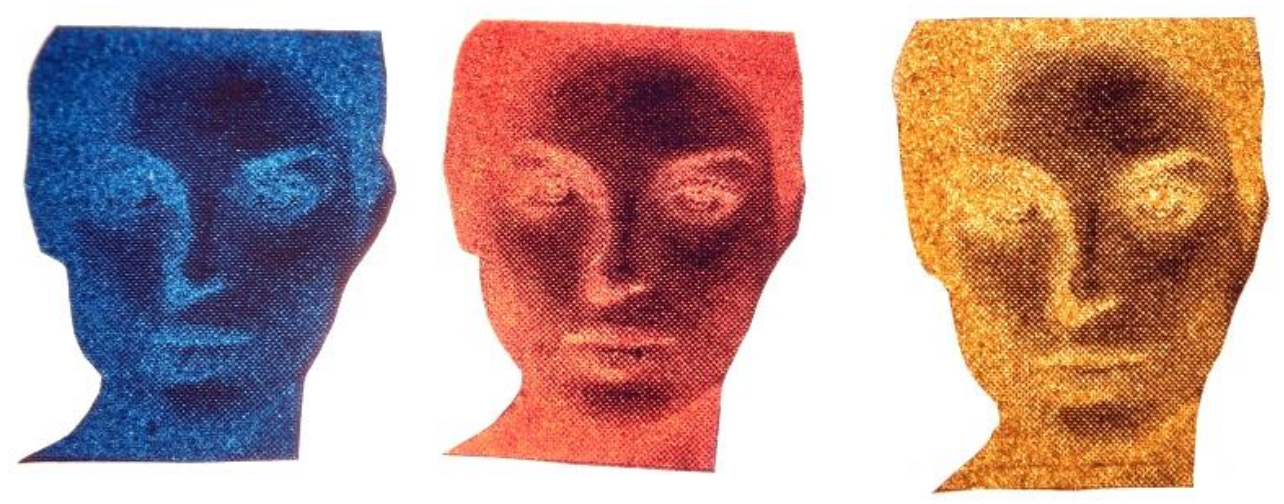

c)

Figure 4. A protective image to protect passports and other identity documents against falsification, which can be produced in one copy within 20 seconds:

a) in reflected light; b) black-and-white image in transmitted light;

c) color image in transmitted light

A new effect of the nanowhiskers growth in the open air in laser-induced plasma was confirmed by a large number of reproducible experiments (Honma, 2010; Zohuri, 2021; Qibiao, et al. 2019), which provided the growth of nanowhiskers consisting of metals and their alloys, various oxides, semi-precious stones, glasses, and composite materials (Maksimovsky y Radutsky, 2014a; Maximovskii et al. 2016; Maksimovsky y Radutsky, 2004; Maksimovsky y Stavtsev y Nedelkin, 2017; Hosokawa et al. 2013; Ivanov, et al. 2014; Maksimovsky y Radutsky, 2014b; 2015; Bogonosov y Stavtsev y Maksimovsky, 2018; Maksimovsky y Ivanova y Stavtsev, 2018; Maksimovsky y Stavtsev y Ivanova, 2019; Maksimovsky y Stavtsev y Ovsyannikova, 2019).

Nanowhiskers, grown by this method, allow increasing the surface activity of materials by several hundred thousand times (Hosokawa et al. 2013). One or several atoms with unpaired electrons at the tips of whiskers radically change the physical and chemical properties of the material.

For the first time, V.V. Osiko offers the idea of coherent crystal binding and claims that nanowhiskers prefer to crystallize in the form of double crystals. The generation of double crystals is a distinctive feature of the growth of nanowhiskers according to the mechanism of oriented binding.

There are articles on the binding of oriented nanoparticles, which are also observed in glasses (Ivanov et al. 2014).

\section{CONCLUSIONS}

The article shows experimental detection of inhomogeneity of the laser beam. Even though Askaryan considered this effect harmful (Askaryan, 1974) when transmitting high energy densities, the application of this effect to surface modification gives new results.

The discovery of this effect gives hope for the development in Russia of a new area in the field of engineering and technology for the production of chemical catalysts, lithium batteries and accumulators, solar cells, quantum communication systems, and other specialized applications. One of the practical applications of nanowhiskers, grown in laser-induced plasma is the technology for reliable protection of paper documents (Maksimovsky y Radutsky, 2014a; 2004), printing processes (Maksimovsky y Radutsky, 
2014b; 2015; Bogonosov y Stavtsev y Maksimovsky, 2018), and plastic products (Maksimovsky y Stavtsev y Nedelkin, 2017; Hosokawa et al. 2013; Ivanov, et al. 2014; Maksimovsky y Radutsky, 2014b; 2015; Bogonosov y Stavtsev y Maksimovsky, 2018; Maksimovsky y Ivanova y Stavtsev, 2018; Maksimovsky y Stavtsev y Ivanova, 2019; Maksimovsky y Stavtsev y Ovsyannikova, 2019). To protect passports and other identity documents against falsification, the photo shown in Figure 4, can be made in one copy in 20 seconds.

All these factors allow concluding that a new field is emerging in science and technology, namely, nanowhiskerography.

Below are some vivid examples of the created images that demonstrate the potential of the new features of the method.

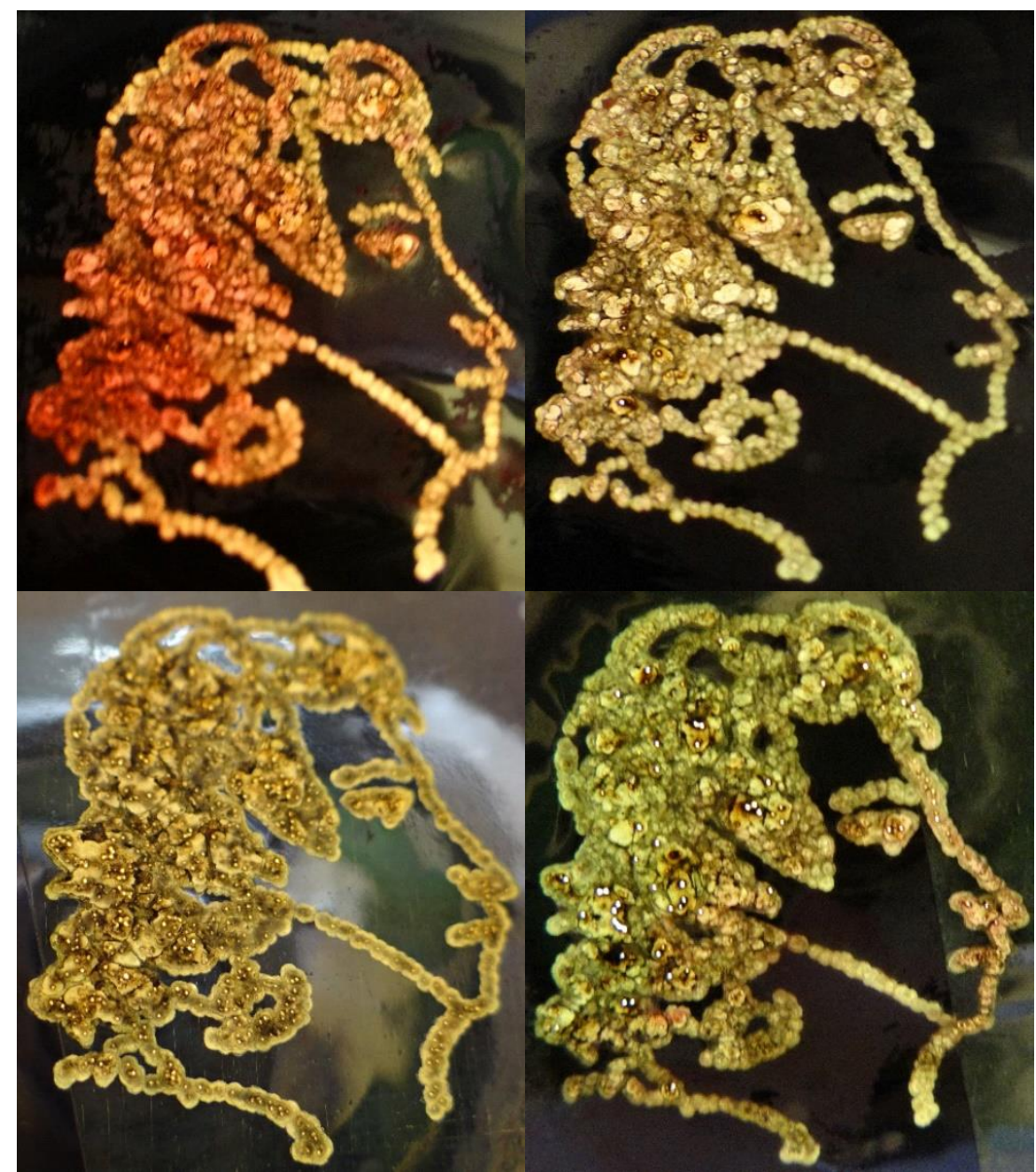

Figure 5. Single crystals of shattuckite in paper

The existing possibility of controlled change in the deviation from stoichiometry in the material allows changing the color of single crystals of shattuckite obtained for the first time in the laboratory. The technology allows for the co-crystallization of any materials due to high pressures and temperatures. A similar process can be observed in the bowels of the Earth (Maximovskii et al. 2016).

\section{ACKNOWLEDGMENT}

The reported study was funded by RFBR, project number No. 19-32-90063\19. 


\section{REFERENCES}

Askaryan, G.A. (1974). Self-Focusing Effect. Sov. Phys. Usp., 15, 680, http://dx.doi.org/10.1070/PU1973v015n04ABEH005005

Askaryan, G.A., Moroz, E.P. (1962). Pressure during evaporation of a substance in an irradiation beam. ZhETF, 43(6), 2319-2320.

Bogonosov, K.A., Maksimovsky, S.N. (2011). Rapid crystallization of copper in low-temperature laser plasma. Reports of the Academy of Sciences, 439(5), 605-608.

Bogonosov, K.A., Stavtsev, A.Yu., Maksimovsky, S.N. (2018). Mechanisms of rapid crystallization of metals and fields of their application. International Journal of Mechanical Engineering and Technology (IJMET), 9(1), 774-785.

Chiao, R.Y., Garmire, E., Townes, C.H. (1964). Self-Trapping of Optical Beams. Phys. Lett., 13, 479 (964). http://dx.doi.org/10.1103/PhysRevLett.13.479

Givargizov, E.I., Chernov, A.A. (1973). Crystallography 18(1), 147.

Honma, T. (2010). Laser-induced crystal growth of nonlinear optical crystal on the glass surface. Ceramic Society, Japan, 71-76. http://dx.doi.org/10.2109/jcersj2.118.71

Hosokawa, M., Nogi, K., Naito, M., Yokoyama, T. (2013). Nanoparticle Technology Handbook. Scientific World.

Ivanov, V.K., Fedorov, P.P., Baranchikov, A.E., Osiko, V.V. (2014). Oriented particle splicing: 100 years of research on the non-classical mechanism of crystal growth. Advances in Chemistry, 83(12), 1204-1222.

Koshelev, A.V., Zvereva, E.A., Chareev, D.A., Volkova, O.S., Vymazalova, A, Laufek, F, et al. (2016). The long-range magnetic order and underlying spin model in shattuckite $\mathrm{Cu}_{5}\left(\mathrm{SiO}_{3}\right)_{4}(\mathrm{OH})$. Physics and Chemistry of Minerals, 43(1), 43-49. http://dx.doi.org/10.1007/s00269-015-0772-7.

Kudryashov, S.I., Lyon, K., Allen, S.D. (2006). Near-field thermal radiative transfer and thermoacoustic effects from vapor plumes produced by pulsed $\mathrm{CO}_{2}$ laser ablation of bulk water. Journal of Applied Physics, 100(12), 124908. http://dx.doi.org/10.1063/1.2402388.

Kumn, Th.S. (1962). The structure of scientific revolutions. University of Chicago Press.

Maksimovsky, S.N., Ivanova, V.N., Stavtsev, A.Yu. (2018). Nanowhiskerography - a new method of security printing using scanning laser radiation. Bulletin of the Lebedev Physics Institute, 45(11), 341345.

Maksimovsky, S.N., Radutsky, G.A. (2004). A method for forming nanoscale clusters and creating ordered structures from them. Patent of the Russian Federation No. 2279400, priority of 26.10.04.

Maksimovsky, S.N., Radutsky, G.A. (2014a). A method for creating an image from crystals of various materials, visible to the naked eye in the transmitted and reflected light in the body of sheet material. Patent of the Russian Federation No. 2532154. 
Maksimovsky, S.N., Radutsky, G.A. (2014b). A method for creating an individual image iridescent with rainbow colors to protect against the forgery of an identity document. Patent of the Russian Federation No. 2658492 (application No. 201711978).

Maksimovsky, S.N., Radutsky, G.A. (2015). A method for enhancing the glow of an image iridescent with rainbow colors, created in the body of sheet material. Patent of the Russian Federation No. 2537837.

Maksimovsky, S.N., Stavtsev, A.Yu., and Nedelkin, V.I. (2017). Interaction of pulsed laser radiation with a polycarbonate-based composite. Bulletin of the Lebedev Physics Institute, 44(12), 374-379.

Maksimovsky, S.N., Stavtsev, A.Yu., Ivanova, V.N. (2019). Coherent nanowhiskerography. Journal of Materials Science Research, 8(2), 183-192.

Maksimovsky, S.N., Stavtsev, A.Yu., Ovsyannikova, A.V. (2019). Growth of coherent whiskers on polycarbonate substrates by laser radiation. Journal of Russian Laser Research, 40(2), 197-204.

Maximovskii, S., Turyanskiy, A., Bogonosov, K., Gizha, S., Senkov, V., Pirshin, I. (2016). Shattuckite synthesis and the pattern formation by the scanning laser beam. Tecnol. Metal. Mater. Miner, San Paulo, 13(3), 248-251.

Popper, K. (1959). The logic of scientific discovery.

Qibiao, Ya., Yang, Ch., Zhihuai, L., Lie, Ch. et al. (2019). Nanosecond laser surface processing of AlN ceramics. Journal of Materials Science, 54(6). http://dx.doi.org/10.1007/s10853-019-03888-9

Zohuri, B. (2021). Laser surface processing. Thermal effects of high power laser energy on materials, 331 362. http://dx.doi.org/10.1007/978-3-030-63064-5 6 